This is a postprint version of the following published document:

Madrid, J. M., Pozuelo, J., Mendicuti, F. \& Mattice, W. L. (1997): Molecular Mechanics Study of the Inclusion Complexes of 2-Methyl Naphthoate with $\alpha$ - and $\beta$ Cyclodextrins. Journal of Colloid and Interface Science, 193 (1), pp.: 112-120.

DOI: $10.1006 /$ jcis. 1997.5061

(C) Elsevier, 1997

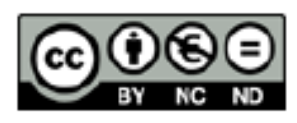

This work is licensed under a Creative Commons Attribution-NonCommercialNoDerivatives 4.0 International License. 


\title{
Molecular Mechanics Study of the Inclusion Complexes of 2-Methyl Naphthoate with - - and - -Cyclodextrins
}

\author{
Jose Manuel Madrid,* Javier Pozuelo, ${ }^{*}$ Francisco Mendicuti, * and Wayne L. Mattice ${ }^{1,} \dagger$ \\ * Departamento de Quimica Fisica, Universidad de Alcala, 28871 Alcala de Henares, Madrid, Spain; \\ and $\dagger$ Institute of Polymer Science, University of Akron, Akron, Ohio 44325-3909
}

Molecular mechanics calculations were employed to study the inclusion of 2-methyl naphthoate in - - and • -cyclodextrin in vacuo and in the presence of water as a solvent. The driving forces for complexation are dominated by nonbonded van der Waals host:guest interactions in both environments. The 2-methyl naphthoate penetrates completely into the cavity of $\bullet$-cyclodextrin, but there is only partial penetration by the same molecule into the smaller cavity of - -cyclodextrin. 1997 Academic Press

Key Words: cyclodextrins; inclusion complexes.

\section{INTRODUCTION}

Cyclodextrins (CDs) are toroid-shaped cyclic oligosaccharides composed of six $(\bullet-C D)$, seven $(\bullet-C D)$, eight $(\bullet-$ $\mathrm{CD})$, or more D- $(\bullet)$-glucopyranose units joined by $\bullet-(1,4)$ linkages. These cyclic oligosaccharides have attracted attention because they spontaneously form inclusion complexes with a variety of guest molecules in aqueous media, since the internal cavity of the $\mathrm{CD}$ is more hydrophobic than the aqueous environment (1-3). Several experiments have been used to obtain the structural and thermodynamic parameters associated with the formation of the CD:guest inclusion complex (1-4). Among these methods are UV-visible absorption (5-9), nuclear magnetic resonance (10), circular dichroism $(11,12)$, potentiometry $(13,14)$, polarography $(15$, 16), liquid chromatography (17-20), fluorescenc spectroscopy $(6,12,21-25)$, X-ray crystallography (26), and electron spin resonance (ESR) spectroscopy $(27,28)$.

Complexation processes in solution depend on the size, shape, and hydrophobicity of the guest molecule. The driving forces that have been proposed include van der Waals interactions between guest and host, hydrogen bonding between the guest and the hydroxyl groups of the $C D$, release of strain energy in the macromolecular ring of the $\mathrm{CD}$, and dipole-dipole and/or electronic charge interactions (1-3).
Molecular mechanics (MM) (29-31) and molecular dynamics (MD) (32-36) calculations have been performed in computational studies of the molecular structures and conformations of CDs in isolation, solvated by water, and in their crystalline forms. The application of these computational techniques to $\mathrm{CD}$ :guest inclusion compounds for a better understanding of the complexation process itself, however, has been more limited. Earlier MM works are from Harata (37) and Tabushi et al. (38). More recently, MM studies that use mainly MM2, MM3, and AMBER force field have been performed by Menger and Sherrod (39), Venananzi et al. (40), Ohashi et al. (41), Jaime and coworkers (42-46), Lipkowitz et al. (47), and Berg et al. (48). Ivanov and Jaime have also attempted MD studies of $\mathrm{CD}$ in the presence of water as a solvent (46).

Recently inclusion complexes of 2-methyl naphthoate $(\mathrm{MN})$ with - -CD and - -CD were studied by steady-state fluorescenc (49). The stoichiometry and formation constants were obtained from the ratio of the emission intensities for two bands of $\mathrm{MN}$ that are sensitive to the polarity of the medium. One-to-one stoichiometry was obtained for MN: $\mathrm{CD}$ and $\mathrm{MN}:-\mathrm{CD}$ complexes, but the equilibrium constants for formation at $25^{\circ} \mathrm{C}$ differ by an order of magnitude, being $200 \cdot 20$ and $1965 \cdot 160 M^{*}$, respectively. The experiments showed that the formation of $\mathrm{MN}:-\mathrm{CD}$ is accompanied by a more negative enthalpy change, $\cdot H$, than the formation of $\mathrm{MN}:-\mathrm{CD}$. The change in entropy, $S$, was obviously important in determining the stability of both complexes. The formation of the MN: -CD complex was accompanied by a large negative $S$, but the entropy increased on formation of the MN: -CD complex. Anisotropy measurements were used to interpret the different signs of $-S$. Two possible contributing factors are (1) - -CD insulates $\mathrm{MN}$ from the solvent better than does - $-\mathrm{CD}$, and (2) MN may have more rotational freedom inside the larger cavity of - $\mathrm{CD}$, as compared with the smaller cavity of - $-\mathrm{CD}$.

Here we report the results of MM studies on the complexes of $\mathrm{MN}$ with - $\mathrm{CD}$ and - $\mathrm{CD}$ in vacuo and in the presence of water, using the Tripos Force Field (50) of 
TABLE 1

Bond Lengths, Bond Angles, and Partial Charges in a D-Glucopyranose Unit in - CD (or - -CD) ${ }^{a}$

\begin{tabular}{|c|c|c|c|c|c|}
\hline Bond & $\begin{array}{l}\text { Length } \\
\text { (A) }\end{array}$ & Bonds & $\begin{array}{l}\text { Angle } \\
\text { (deg) }\end{array}$ & Atom $^{b}$ & $\begin{array}{c}\text { Charge } \\
\text { (esu) }\end{array}$ \\
\hline $\mathrm{C} 1-\mathrm{C} 2$ & $1.547(1.547)$ & $\mathrm{O} 5-\mathrm{C} 1-\mathrm{C} 2$ & $109.0(109.9)$ & $\mathrm{C} 1$ & $0.327(0.327)$ \\
\hline $\mathrm{C} 2-\mathrm{C} 3$ & $1.546(1.544)$ & $\mathrm{C} 1-\mathrm{C} 2-\mathrm{C} 3$ & $109.8(109.1)$ & $\mathrm{C} 2$ & $0.096(0.096)$ \\
\hline $\mathrm{C} 3-\mathrm{C} 4$ & $1.550(1.554)$ & $\mathrm{C} 2-\mathrm{C} 3-\mathrm{C} 4$ & $110.2(109.7)$ & $\mathrm{C} 3$ & $0.098(0.098)$ \\
\hline $\mathrm{C} 4-\mathrm{C} 5$ & $1.556(1.558)$ & $\mathrm{C} 4-\mathrm{C} 5-\mathrm{C} 5$ & $109.2(108.1)$ & $\mathrm{C} 4$ & $0.121(0.121)$ \\
\hline $\mathrm{C} 5-\mathrm{O} 5$ & $1.446(1.444)$ & $\mathrm{C} 4-\mathrm{C} 5-\mathrm{O} 5$ & $111.6(110.1)$ & $\mathrm{C} 5$ & $0.144(0.144)$ \\
\hline $\mathrm{C} 1-\mathrm{O} 5$ & $1.438(1.437)$ & $\mathrm{C} 5-\mathrm{O} 5-\mathrm{C} 1$ & 114.0 (114.3) & $\mathrm{C} 6$ & $0.167(0.167)$ \\
\hline $\mathrm{C} 2-\mathrm{O} 2$ & $1.440(1.440)$ & $\mathrm{C} 1-\mathrm{C} 2-\mathrm{O} 2$ & $109.2(109.2)$ & $\mathrm{O} 2$ & $\cdot 0.315(\cdot 0.315)$ \\
\hline $\mathrm{C} 3-\mathrm{O} 3$ & 1.439 (1.439) & $\mathrm{O} 2-\mathrm{C} 2-\mathrm{C} 3$ & 110.4 (110.6) & $\mathrm{O} 3$ & $\cdot 0.330(\cdot 0.330)$ \\
\hline $\mathrm{C} 4-\mathrm{O} 4$ & 1.449 (1.446) & $\mathrm{C} 2-\mathrm{C} 3-\mathrm{O} 2$ & $108.7(108.0)$ & $\mathrm{O} 4$ & $\cdot 0.359(\cdot 0.359)$ \\
\hline $\mathrm{C} 5-\mathrm{C} 6$ & $1.550(1.551)$ & $\mathrm{O} 3-\mathrm{C} 3-\mathrm{C} 4$ & $110.2(112.5)$ & O5 & $\cdot 0.352(\cdot 0.352)$ \\
\hline $\mathrm{C} 6-\mathrm{O} 6$ & $1.438(1.440)$ & $\mathrm{C} 3-\mathrm{C} 4-\mathrm{O} 4$ & $102.7(105.5)$ & 06 & $\cdot 0.317(\cdot 0.317)$ \\
\hline \multirow[t]{7}{*}{$\mathrm{C} 1-4^{\prime}$} & $1.446(1.442)$ & $\mathrm{O} 4-\mathrm{C} 4-\mathrm{C} 5$ & 114.5 (115.3) & & \\
\hline & & $\mathrm{C} 4-\mathrm{C} 5-\mathrm{C} 6$ & 111.5 (113.7) & & \\
\hline & & $\mathrm{C} 6-\mathrm{C} 5-\mathrm{O} 5$ & 106.1 (104.5) & & \\
\hline & & $\mathrm{C} 5-\mathrm{C} 6-\mathrm{O} 6$ & $110.1(108.6)$ & & \\
\hline & & $\mathrm{O}^{\prime}-\mathrm{C} 1-\mathrm{C} 2$ & 106.8 (109.2) & & \\
\hline & & $\mathrm{C} 4-\mathrm{O} 4-\mathrm{Cl}^{\prime}$ & $117.3(115.6)$ & & \\
\hline & & $\mathrm{O}^{\prime}-\mathrm{C} 1-\mathrm{O} 5$ & 113.7 (111.5) & & \\
\hline
\end{tabular}

${ }^{a}$ Values for $-\mathrm{CD}$ are in parentheses.

${ }^{b}$ Charges for hydrogen atoms (not tabulated) produce a neutral molecule.

Sybyl 6.2 (51). The results are discussed in relationship to the thermodynamic parameters associated with the formation of the complexes and their implications for the driving forces responsible for the process of inclusion.

\section{METHODS}

\section{Computational Details}

The calculations were performed with Sybyl 6.2 (51) using the Tripos Force Field (50). This force fiel approximates the conformational energy of a molecule as the sum of terms for bond stretching, angle bending, torsion, van der Waals, electrostatic, and out-of-plane (for aromatic conjugated systems) interactions. A relative permittivity of 3.5 was used for the electrostatic interactions. Use of a value as low as one for the relative permittivity has little effect on the results because electrostatic interactions are not an important source of the stabilization of the complex. The host (CDs) and guest $(\mathrm{MN})$ geometry and charges obtained by AM1 from MOPAC (52) are collected in Tables 1 and 2, respectively. The same charges were used previously for the CDs (36). Extended nonbonded cutoff distances were $8 \AA$ for van der Waals and electrostatic interactions. A few trial calculations using the larger cutoff of $20 \AA$ did not change the total potential energy more than $0.12 \%$. Minimization of the potential energy of the system was performed by the simplex algorithm $(53,54)$, and conjugate gradient was used as a termination method (54). The termination gradients were 0.2 and 3.0 for the calculations performed in vacuo and in water, respectively. Geometry and charges for water molecules, which were also obtained by MOPAC (52), are a bond length of $0.95 \AA$, a bond angle of $104.5^{\circ}$, and partial charges of 0.192 and $\bullet 0.394$ esu for hydrogen and oxygen atoms, respectively. Aqueous solvation was achieved by using the Molecular Silverware (55) algorithm (MS), which rapidly packs solvent molecules around the solute. The implementation of MS in Sybyl builds a periodic box by adding solvent molecules so that the solvent van der Waals surface does not overlap with the van der Waals surface of the solute. Periodic boundary conditions were employed using a cubic box with sides of 31.62 and $31.87 \AA$ for $\mathrm{MN}:-\mathrm{CD}$ and $\mathrm{MN}:-\mathrm{CD}$ complexes, respectively.

\section{Starting Conformations}

The initial conformation for $\mathrm{MN}$, depicted in Fig. 1, is one of the conformational energy minima where the ester group and the aromatic ring are coplanar, and the torsional angle $\mathrm{C}-\mathrm{CO}-\mathrm{O}-\mathrm{CH}_{3}$ is in the trans state. The initial structures for the CDs were nondistorted, as described previously (36). Following the usual nomenclature, the torsional angles - and - were $0^{\circ}$ and $\cdot 3^{\circ}$, respectively, and the bond angle at the bridging oxygen atom, $\bullet$, for the $\bullet-1,4$ linkages was $130.3^{\circ}$ and $121.7^{\circ}$ for $-\mathrm{CD}$ and $-\mathrm{CD}$, respectively. The $\bullet$ dihedral angles were initially in the trans conformation. The nondistorted $C D$ torus approximates a truncated cone with bases of radii $R$ and $r$, define by the average of the distances 
TABLE 2

Bond Lengths, Bond Angles, and Partial Charges in 2-Methyl Naphthoate

\begin{tabular}{|c|c|c|c|c|c|}
\hline Bond & $\begin{array}{l}\text { Length } \\
\text { (A) }\end{array}$ & Bonds & $\begin{array}{c}\text { Angle } \\
(\mathrm{deg})\end{array}$ & Atom $^{a}$ & $\begin{array}{c}\text { Charge } \\
\text { (esu) }\end{array}$ \\
\hline $\mathrm{C} 1-\mathrm{C} 2$ & 1.397 & $\mathrm{C} 1-\mathrm{C} 2-\mathrm{C} 3$ & 119.9 & $\mathrm{C} 1$ & $\cdot 0.106$ \\
\hline $\mathrm{C} 2-\mathrm{C} 3$ & 1.397 & $\mathrm{C} 2-\mathrm{C} 3-\mathrm{C} 4$ & 119.9 & $\mathrm{C} 2$ & • 0.132 \\
\hline $\mathrm{C} 3-\mathrm{C} 4$ & 1.397 & $\mathrm{C} 3-\mathrm{C} 4-\mathrm{C} 10$ & 120.3 & $\mathrm{C} 3$ & $\cdot 0.114$ \\
\hline $\mathrm{C} 4-\mathrm{C} 10$ & 1.400 & $\mathrm{C} 4-\mathrm{C} 10-\mathrm{C} 9$ & 119.7 & $\mathrm{C} 4$ & - 0.128 \\
\hline $\mathrm{C} 10-\mathrm{C} 5$ & 1.400 & $\mathrm{C} 10-\mathrm{C} 9-\mathrm{C} 1$ & 119.7 & C5 & $\cdot 0.132$ \\
\hline $\mathrm{C} 5-\mathrm{C} 6$ & 1.400 & $\mathrm{C} 9-\mathrm{C} 1-\mathrm{C} 1$ & 120.3 & C6 & $\cdot 0.094$ \\
\hline $\mathrm{C} 6-\mathrm{C} 7$ & 1.397 & $\mathrm{C} 10-\mathrm{C} 5-\mathrm{C} 6$ & 120.3 & C7 & • 0.109 \\
\hline $\mathrm{C} 7-\mathrm{C} 8$ & 1.397 & $\mathrm{C} 5-\mathrm{C} 6-\mathrm{C} 7$ & 119.9 & $\mathrm{C} 8$ & - 0.048 \\
\hline $\mathrm{C} 8-\mathrm{C} 9$ & 1.397 & $\mathrm{C} 6-\mathrm{C} 7-\mathrm{C} 8$ & 119.9 & C9 & $\cdot 0.048$ \\
\hline $\mathrm{C} 9-\mathrm{C} 1$ & 1.400 & $\mathrm{C} 7-\mathrm{C} 8-\mathrm{C} 8$ & 120.3 & $\mathrm{C} 10$ & $\cdot 0.011$ \\
\hline $\mathrm{C} 9-\mathrm{C} 10$ & 1.402 & $\mathrm{C} 8-\mathrm{C} 9-\mathrm{C} 10$ & 119.7 & $\mathrm{C} 11$ & 0.330 \\
\hline C7-C11 & 1.510 & $\mathrm{C} 9-\mathrm{C} 10-\mathrm{C} 5$ & 119.7 & $\mathrm{C} 12$ & $\cdot 0.075$ \\
\hline $\mathrm{C} 11-\mathrm{O} 1$ & 1.230 & $\mathrm{C} 1-\mathrm{C} 9-\mathrm{C} 8$ & 120.5 & 01 & $\cdot 0.370$ \\
\hline $\mathrm{C} 11-\mathrm{O} 2$ & 1.334 & $\mathrm{C} 4-\mathrm{C} 10-\mathrm{C} 5$ & 120.5 & $\mathrm{O} 2$ & $\cdot 0.227$ \\
\hline $\mathrm{O} 2-\mathrm{C} 12$ & 1.430 & & & & \\
\hline
\end{tabular}

${ }^{a}$ Charges for hydrogen atoms (not tabulated) produce a neutral molecule.

from all oxygen atoms of the secondary and primary hydroxy groups, respectively, to the centers $C$ and $C^{\prime}$, define by these oxygen atoms. The initial estimates of $R$ and $r$ for - -CD (•-CD) were 3.57 and $3.55 \AA$ (4.31 and $4.34 \AA$ ), respectively (36). These values were corrected by subtracting the van der Waals radius of the oxygen atoms (1.36 $\AA)$. The depth of the torus, which in both cases is $8.81 \AA$, was obtained by taking the distance between both centroids $C$ and $C^{\prime}$, and corrected by adding twice the van der Waals radius of oxygen. With these parameters, the initial volumes of the cavities were 351 and $518 \AA^{3}$ for - -CD and - -CD, respectively (36).

\section{Complexation}

The origin of a Cartesian coordinate system (denoted by $O$ in Fig. 1) was located at the center of mass of the oxygen atoms of the hydroxyl groups. The $y$ axis of this coordinate system passes through the centroids def ned previously as $C$ and $C^{\prime}$. It is oriented with the $y$ coordinates of the oxygen atoms in the primary (secondary) hydroxyl groups being negative (positive). It constitutes sixfold and sevenfold rotation axes for the initial conformations of - $-C D$ and $--C D$, respectively. The $y z$ plane includes one of the glycosidic oxygen atoms. All glyco-

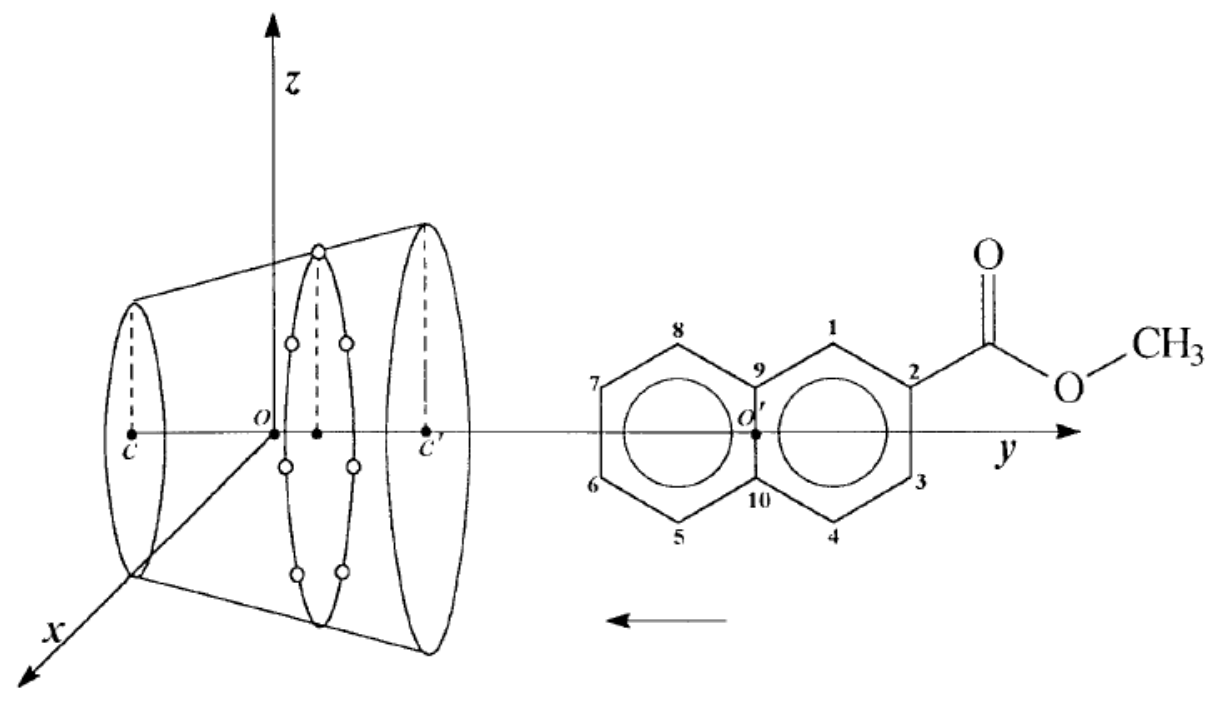

FIG. 1. Coordinate system used to defin the process of complexation. 

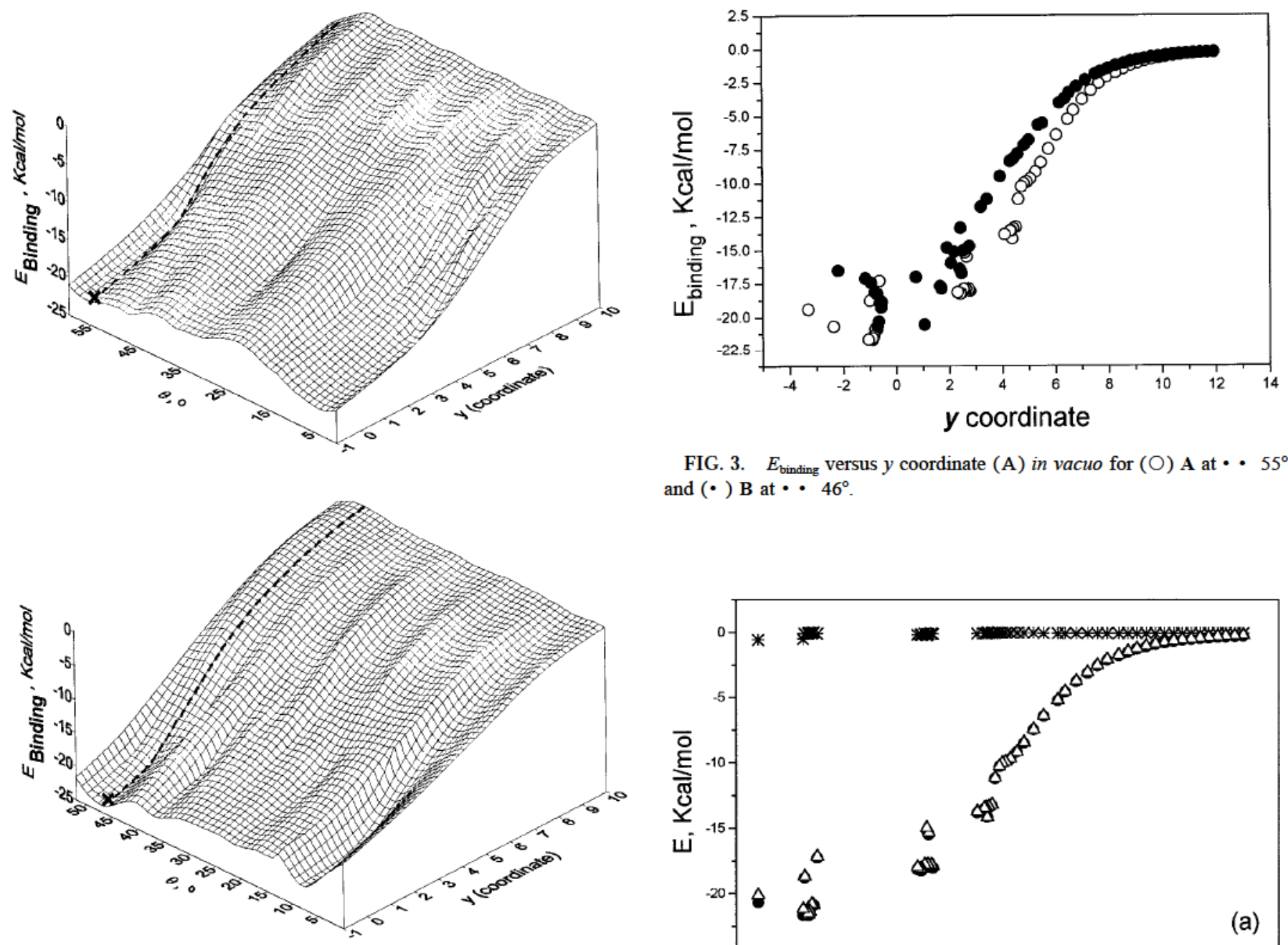

FIG. 2. Three-dimensional plot of $E_{\text {binding }}$ versus - and the distance ( $y$, in A) between the host and guest for (top) $\mathbf{A}$ and (bottom) B. The trajectory of lowest energy is highlighted. The $y$ axis is a six (seven)fold rotation axis for $\mathbf{A}$ (B).

sidic oxygen atoms are placed in a plane nearly parallel to the $x z$ plane, with a $y$ coordinate initially at $0.6 \AA$. For the complexation process, the host CD was kept in this position while the guest $\mathrm{MN}$ approached along the $y$ axis, from the positive direction, so that $\mathrm{MN}$ approaches the wider edge of the torus. The $y$ axis and the one that bisects the $\mathrm{C} 2-\mathrm{C} 3, \mathrm{C} 6-\mathrm{C} 7$, and $\mathrm{C} 9-\mathrm{C} 10$ bonds of the naphthalene group were colinear during the approach, as shown in Fig. 1. The distance along the $y$ axis, from $O$ to the centroid $O^{\prime}$ of the $\mathrm{C} 9$ and $\mathrm{C} 10$ atoms, was used as a measure of the distance between host and guest. The angle - between the $y z$ plane and the plane of the naphthalene ring was used to def ne the orientation of $\mathrm{MN}$ relative to the host. The calculations reported here were performed where the apolar side of the naphthalene (without the ester) approaches the host, as depicted in Fig. 1. The use
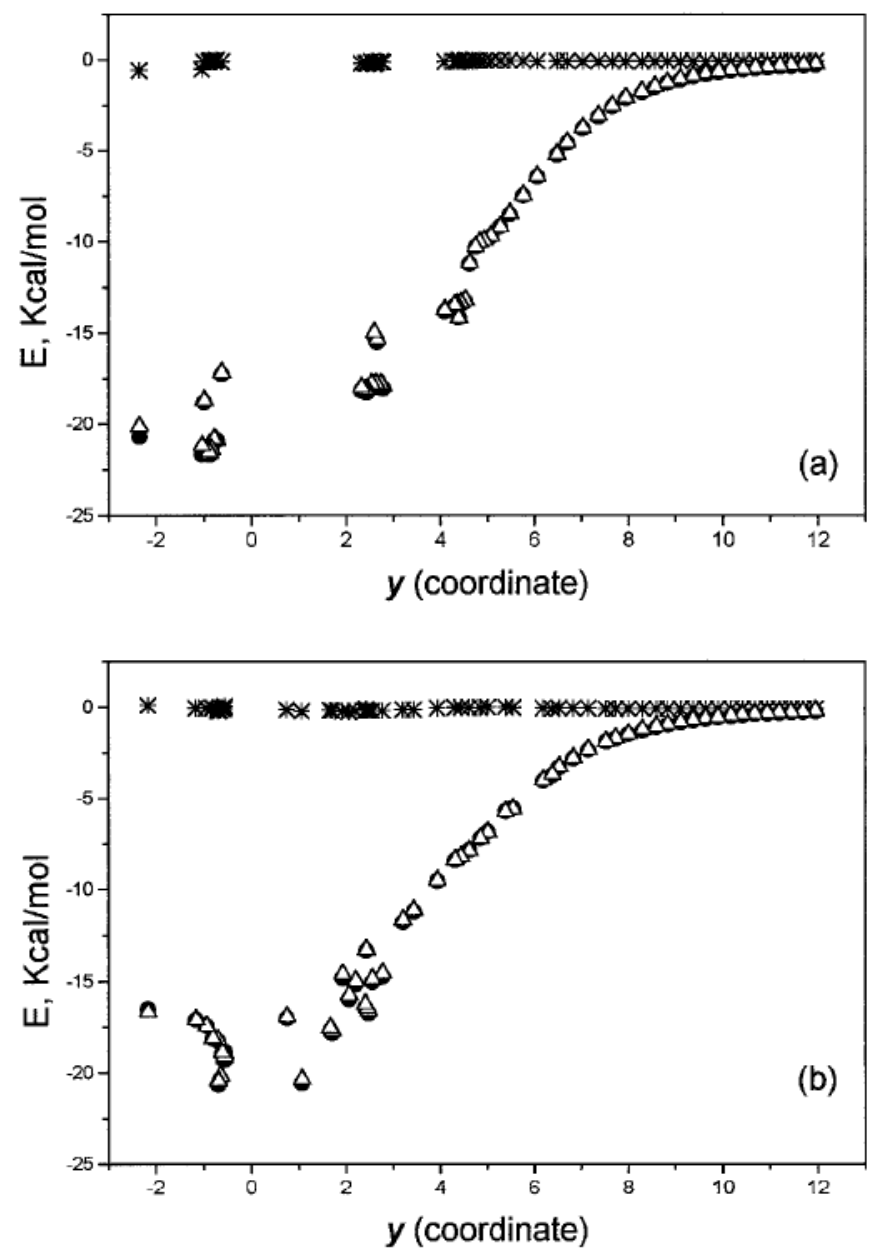

FIG. 4. Van der Waals $(\triangle)$ and electrostatic (*) contributions to $E_{\text {binding }}$ (- ), as a function of the $y$ coordinate (A), for (a) A, using $\cdots 55^{\circ}$, and (b) B, using $\cdots 46^{\circ}$. The triangles overlay most of the fille circles. 
TABLE 3

$E_{\text {binding }}$ and Selected Components at the Minimum Energy (Subscript 0) and Infinite Separation of the Two Components (Subscript $\infty$ )

\begin{tabular}{|c|c|c|c|c|}
\hline & \multicolumn{4}{|c|}{ Energy $(\mathrm{kcal} / \mathrm{mol})$} \\
\hline & $\mathbf{A}_{0}$ & $\mathbf{A}_{\infty}$ & $\mathbf{B}_{0}$ & $\mathbf{B}_{\infty}$ \\
\hline$E_{\text {binding }}$ & $\cdot 21.7$ & $\cdot 0.2$ & • 20.6 & $\cdot 0.2$ \\
\hline Electrostatic part & $\cdot 0.1$ & $\cdot 0.0$ & $\cdot 0.2$ & $\cdot 0.0$ \\
\hline Van der Waals part & $\cdot 21.6$ & $\cdot 0.2$ & $\cdot 20.4$ & $\cdot 0.2$ \\
\hline$E_{\text {tot }}$ for $\mathrm{MN}: \mathrm{CD}$ & 83.8 & 95.6 & 84.4 & 110.6 \\
\hline Electrostatic part & 48.3 & 48.8 & 57.1 & 56.4 \\
\hline Van der Waals part & - 30.5 & - 12.9 & - 33.4 & $\cdot 13.7$ \\
\hline$E_{\text {tot }}$ for $\mathrm{CD}$ & 98.6 & 90.7 & 99.7 & 105.6 \\
\hline Electrostatic part & 46.8 & 47.3 & 56.0 & 54.9 \\
\hline Van der Waals part & $\cdot 11.4$ & $\cdot 15.3$ & $\cdot 15.7$ & $\cdot 16.2$ \\
\hline$E_{\text {tot }}$ for $\mathrm{MN}$ & 6.9 & 5.2 & 5.3 & 5.2 \\
\hline Electrostatic part & 1.5 & 1.5 & 1.5 & 1.5 \\
\hline Van der Waals part & 2.5 & 2.7 & 2.7 & 2.7 \\
\hline
\end{tabular}

of this orientation of $\mathrm{MN}$ is supported by observations that unsubstituted naphthalene also forms the complex $(56,57)$.

The nonbonded interaction between $\mathrm{MN}$ and $\mathrm{CD}$, or binding energy, $E_{\text {binding, }}$, was obtained as

$$
E_{\text {binding }} \cdot E_{\mathrm{MN}: \mathrm{CD}} \cdot\left(E_{\text {isolated MN }} \cdot E_{\text {isolated CD }}\right) .
$$

The terms on the right-hand side represent the potential energy of the $\mathrm{MN}: \mathrm{CD}$ system and the sum of the potential energies of isolated $\mathrm{MN}$ and $\mathrm{CD}$ in the same conformations. $E_{\text {binding }}$ in the presence of water was obtained by removing the water molecules from the box before applying Eq. [1].

The change in the potential energy of the $\mathrm{CD}$ on complexation was evaluated as the difference in the potential energy of the $\mathrm{CD}$ in the complex and that for the conformation obtained for CD when it is separated from MN by $12 \AA$ (which approximates an infinit separation):

$$
E_{\mathrm{CD}} \cdot E_{\text {complexed CD }} \cdot E_{\text {isolated CD }}
$$

The strain energy, $E_{\text {strain }}$, for CD is def ned as arising only from the local intramolecular contributions and calculated from the torsional, stretching, and bending energies in Eq. [2].

When calculations were performed in the presence of water as a solvent, a measure of the influenc of the solvent on complexation was obtained as the difference between the total potential energy of the entire system $E_{\mathrm{MN}: \mathrm{CD}}$ - water and the sum of the energy of the water molecules $E_{\text {water }}$ contained in the solvent box without taking into account the presence of $\mathrm{MN}$ and $\mathrm{CD}$ and the potential energy of the system
$\mathrm{MN}$ :CD by removing the water molecules from the box, $E_{\mathrm{MN}: \mathrm{CD}}$ :

$$
E_{\mathrm{MN}: \mathrm{CD} \cdot \text { water }} \cdot E_{\mathrm{MN}: \mathrm{CD} \cdot \text { water }} \cdot\left(E_{\mathrm{MN}: \mathrm{CD}} \cdot E_{\text {water }}\right) \text {. }
$$

\section{RESULTS AND DISCUSSION}

\section{Complexation in Vacuo}

As in most of the previous investigations $(37,39-48)$, we initially performed MM simulations of the complexation in the absence of a solvent. The symbols $\mathbf{A}$ and $\mathbf{B}$ refer to $\mathrm{MN}:-\mathrm{CD}$ and $\mathrm{MN}: \bullet-\mathrm{CD}$, respectively.

Initially the path was determined for the most favorable approach of $\mathrm{MN}$ to the $\mathrm{CD}$. For this purpose, $E_{\text {binding }}$ was calculated for all of the optimized structures obtained by scanning - at $10^{\circ}$ intervals from $0^{\circ}$ to $60^{\circ}$ and scanning $y$ at $1-\AA$ intervals where the separation between $\mathrm{CD}$ and $\mathrm{MN}$ was 10 to $2 \AA$. Figure 2 depicts three-dimensional plots of $E_{\text {binding }}$ versus $\cdot$ and $y$ for $\mathbf{A}$ and $\mathbf{B} . E_{\text {binding }}$ passes through
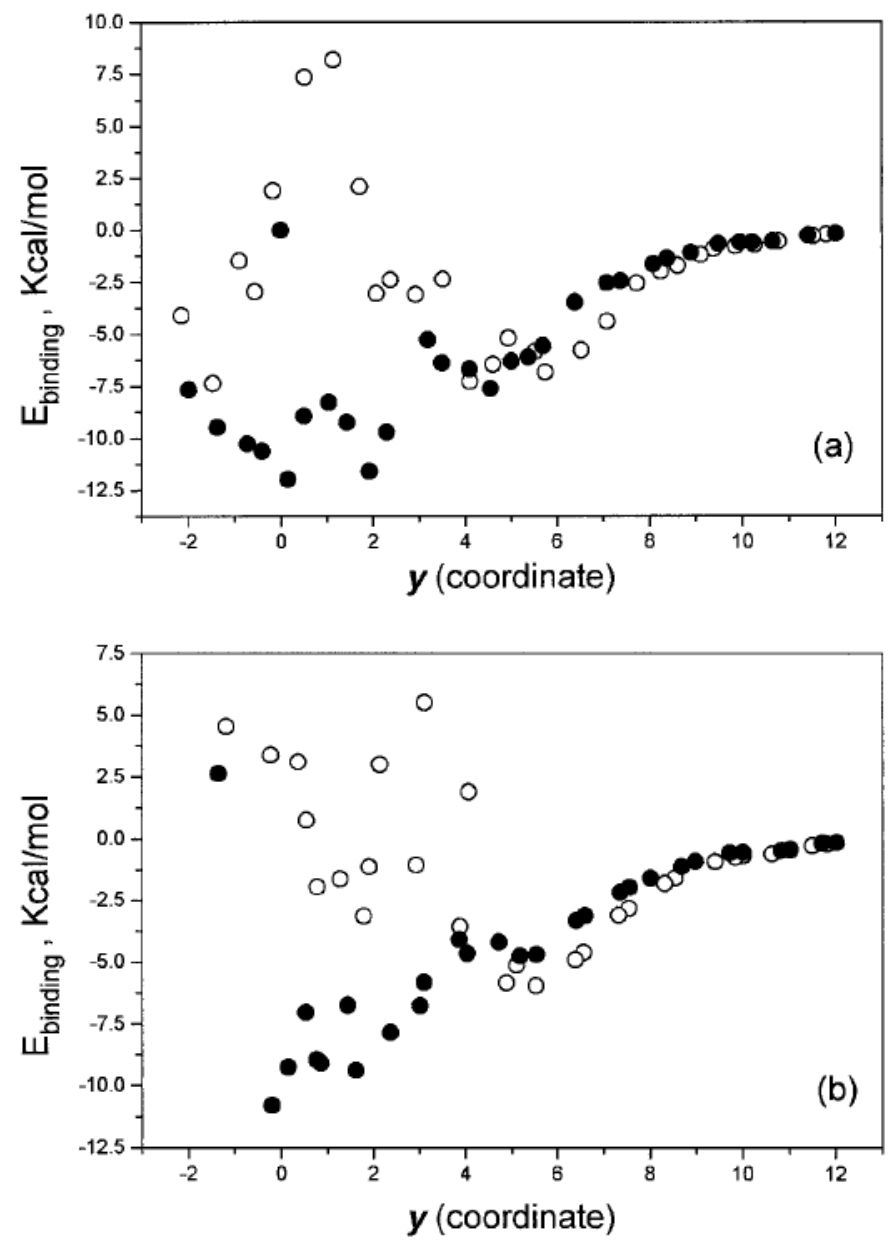

FIG. 5. $E_{\text {binding }}$ as a function of the $y$ coordinate (A) for (O) A (• • $55^{\circ}$ ) and (•) B (• 4 46 ) using Method I (a) and Method II (b). 

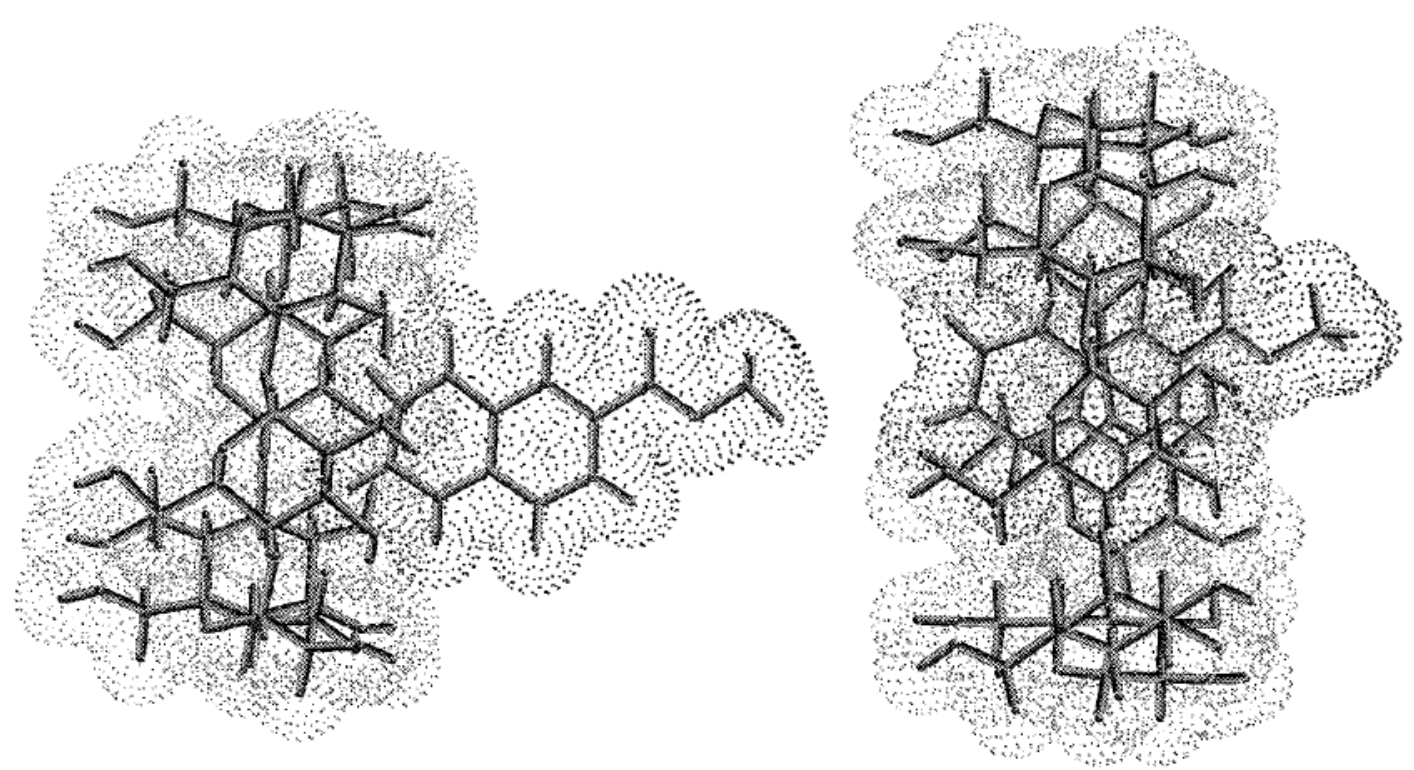

FIG. 6. Van der Waals surfaces for the complexes of (left) A and (right) B. The water molecules are not depicted.

two main minima, which were obtained at approximately $y$ - $1 \AA$ and $\cdots 5^{\circ}$ and $55^{\circ}\left(\bullet 5^{\circ}\right.$ and $\left.46^{\circ}\right)$ for A (B), with the minima for $55^{\circ}$ and $46^{\circ}$ having the more negative $E_{\text {binding }}$. Trajectories of lowest energy for the approach of $\mathrm{MN}$ to $\mathrm{CD}$ were selected from these three-dimensional plots. In the remainder of this work, results were obtained on the basis of the $\mathrm{MN}$ approaching the $\mathrm{CD}$ where $y$ is changed from 12 to $2 \AA$ and $\cdot$ is initially placed at $55^{\circ}$ (A) and $46^{\circ}$ (B) before optimation.

Figure 3 depicts $E_{\text {binding }}$ for $\mathbf{A}$ and $\mathbf{B}$ for the optimized structures obtained by scanning $y$ from 12 to $2 \AA$ at 0.25 $\AA$ intervals for the trajectories of minimum energy. The

\section{TABLE 4}

$E_{\text {binding }}$ and Selected Components at the Minimum Energy (Subscript 0) and Infinite Separation of the Two Components (Subscript $\infty$ ) for the Complexes in Water

\begin{tabular}{lrrrr}
\hline & \multicolumn{4}{c}{ Energy $(\mathrm{kcal} / \mathrm{mol})$} \\
\cline { 2 - 5 } & $\mathbf{A}_{0}$ & \multicolumn{1}{c}{$\mathbf{A}_{\infty}$} & \multicolumn{1}{c}{$\mathbf{B}_{0}$} & $\mathbf{B}_{\infty}$ \\
\hline$E_{\text {binding }}$ & $\cdot 5.9$ & $\cdot 0.2$ & $\cdot 10.8$ & $\cdot 0.2$ \\
Electrostatic part & $\cdot 0.1$ & 0.1 & $\cdot 0.3$ & $\cdot 0.1$ \\
Van der Waals part & $\cdot 5.9$ & $\cdot 0.3$ & $\cdot 10.5$ & $\cdot 0.2$ \\
$E_{\text {tot }}$ for MN:CD & 182.9 & 140.4 & 236.8 & 167.5 \\
Electrostatic part & 47.0 & 46.0 & 55.8 & 54.5 \\
Van der Waals part & 14.2 & 11.6 & $\cdot 2.4$ & 18.6 \\
$E_{\text {tot }}$ for CD & 157.4 & 130.4 & 218.8 & 156.8 \\
Electrostatic part & 45.4 & 44.3 & 54.6 & 53.0 \\
Van der Waals part & 11.4 & 8.2 & 3.9 & 13.3 \\
$E_{\text {tot }}$ for MN & 31.4 & 10.3 & 28.7 & 10.8 \\
Electrostatic part & 1.6 & 1.6 & 1.5 & 1.4 \\
Van der Waals part & 8.6 & 3.6 & 4.2 & 5.4 \\
\hline
\end{tabular}

energy of both systems decreases when $\mathrm{MN}$ approaches the CD. The most stable structure is reached at approximately $y \cdot-1 \AA$ in both cases. At this point the binding energies are very similar. However, the points on the complexation curve for $\mathbf{B}$ are more evenly spaced along $y$ than are the points for $\mathbf{A}$. The gaps for $\mathbf{A}$ at approximately $y \cdot 3.5$ and $0.5 \AA$ are produced by repulsive interactions that are stronger in $\mathbf{A}$ than in B. The firs repulsion is produced by interaction between hydrogen atoms bonded to $\mathrm{C} 5$ and $\mathrm{C} 8$ of $\mathrm{MN}$ and the C3 axial hydrogen atoms of glucopyranose. The second, wider repulsive region is produced by strong interactions of hydrogen atoms bonded to $\mathrm{C} 5$ and $\mathrm{C} 8(\mathrm{C} 1$ and $\mathrm{C} 4)$ from $\mathrm{MN}$ with hydrogen atoms bonded to C3 (C5) of glucopyranose, respectively. Another difference comes from the value of $E_{\text {binding }}$ on complexation. At each $y$ coordinate, the value of $E_{\text {binding }}$ for $\mathbf{A}$ tends to be slightly more negative than that for B. The variation in entropy on complexation has previously been attributed mainly to changes in solvation or in the degrees of freedom of the system during the process (1-3). Assuming that at large distances (when host and guest begin to interact) these entropic effects could be neglected, $E_{\text {binding }}$ will be a measure of the enthalpy, which is slightly more negative for $\mathbf{A}$ than for $\mathbf{B}$. Then the values at the minimum of the curves can be correlated with the equilibrium constant for the process.

Figure 4 depicts the van der Waals and electrostatic contributions to $E_{\text {binding }}$ during the complexation processes. The van der Waals interactions contribute most of the stabilization of both $\mathbf{A}$ and $\mathbf{B}$. From the data collected in lines 7-9 of Table 3 , the total potential energy of the CD ring increases slightly for $\mathbf{A}$ and decreases slight for $\mathbf{B}$, but never makes the primary contribution to the stabilization of the complexes. A similar 

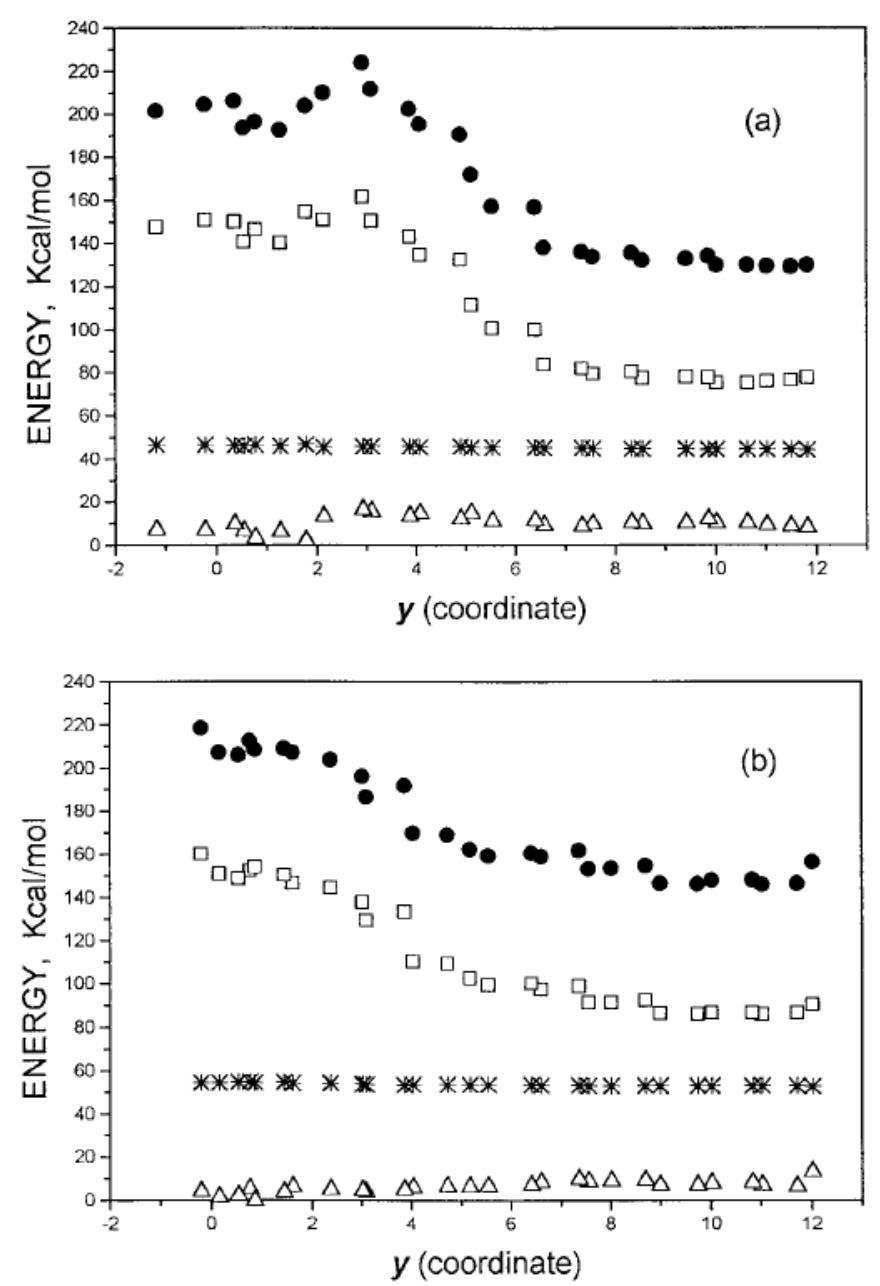

FIG. 7. Energy of the solvated conformation, as a function of $y$ coordinate, for (a) - $-\mathrm{CD}$ and (b) $-{ }_{-} \mathrm{CD}$. The energies, obtained with Method II, are $(\cdot)$ total, $(\triangle)$ van der Waals, (*) electrostatic, and $(\square)$ sum of stretching, bending, and torsions.

statement applies to the sum of the stretching, bending, and torsional energies of the $\mathrm{CD}$. The formation of $\mathbf{A}$ requires a slight increase in these three contributions, but formation of $\mathbf{B}$ is accompanied by a release in strain of the $\mathrm{CD}$ ring, achieved by changes for the $\cdot$ and $\cdot$ torsional angles at the bonds to the bridging oxygen atom.

\section{Complexation in the Presence of Water}

Solvation was performed using two different applications of the Silverware algorithm $(51,55)$. Method $\mathrm{I}$ is a solvation followed by a minimization of the potential energy of each structure generated by changing the distance between $\mathrm{MN}$ and CD. For Method II, the solvation is performed once for the structure generated at $y \cdot 12 \AA$, and the energy of the structure is then minimized. The separation ( $y$ coordinate) between $\mathrm{MN}$ and $\mathrm{CD}$ in the hydrated system is then decreased, and the energy of this new system is again minimized, etc.
Figure 5 depicts $E_{\text {binding }}$ for $\mathbf{A}$ and $\mathbf{B}$ from the optimized structures obtained by scanning $y$ at intervals of $0.5 \AA$. Complexation in the presence of water is also thermodynamically favorable. Methods I and II give similar results, but these results differ from those obtained in vacuo. In Fig. 5 the most stable structure is reached for both methods at approximately $y \cdot 0 \AA$ for $\mathbf{B}$ and around $y \cdot 5 \AA$ for $\mathbf{A}$. In the presence of water, the binding energy for $\mathbf{B}$ is more negative than the binding energy for A. Assuming, as previously, that entropic effects are negligible at large $\mathrm{MN}-\mathrm{CD}$ distances, $E_{\text {binding }}$ would be a measure of the enthalpy, which is more negative for $\mathbf{A}$ than for $\mathbf{B}$. These results agree, at least qualitatively, with the experimental stability constants and enthalpies obtained for $\mathbf{A}$ and $\mathbf{B}$ complexes by fluorescenc measurements (49), which are $\bullet G$ of $\bullet 13.1$ and $\bullet 18.6 \mathrm{~kJ} \mathrm{~mol}^{-1}$ for $\mathbf{A}$ and $\mathbf{B}$, respectively, and $H$ of -30.9 and $\cdot 15.1$ $\mathrm{kJ} \mathrm{mol}{ }^{-1}$ for $\mathbf{A}$ and $\mathbf{B}$, respectively. According to these experimental results, formation of $\mathbf{B}$ is accompanied by a larger negative free energy change and a smaller negative enthalpy change than formation of $\mathbf{A}$.

Since the minimum energy for $\mathbf{B}$ is obtained near $y \cdot 0$ $\AA, \mathrm{MN}$ penetrates completely into the cavity. However, for A the minimum is obtained at approximately $y \cdot 5 \AA$, and $\mathrm{MN}$ penetrates only slightly into the cavity. As a result, - $\mathrm{CD}$ is more effective than - $\mathrm{CD}$ in shielding $\mathrm{MN}$ from the solvent. Figure 6 depicts the structures of both complexes when their energies have been minimized. The differences in $-S$ for the formation of the two complexes may arise from the difference in the exposure of $\mathrm{MN}$ to the solvent, along with the usual entropic effect of the hydrophobic group on the water molecules in its vicinity, as was proposed by Fraiji et al. for similar compounds (24).

The nonbonded van der Waals interactions contribute almost all of the stabilization of the complexes formed in water, as was also true for the complexes in vacuo. The most important components are summarized in Table 4.

The total potential energy of the CDs, as well as several components, is depicted in Fig. 7. Complexation produces an increase in the energy of the $\mathrm{CD}$, with the increase being larger for $\mathbf{A}$ than for $\mathbf{B}$. The increase in energy is due to a change in the conformation of the $\mathrm{CD}$ on formation of the complex. Torsional, bending, and stretching terms contribute most of this increase. There is little contribution from the van der Waals and electrostatic terms.

The energy of the interaction of the solvent with the complexes, denoted by $E_{\mathrm{MN}: \mathrm{CD} \cdot \text { water }}$, is depicted in Fig. 8. This hydration energy is strongly negative when the CD and $\mathrm{MN}$ are separated by a large distance. As they approach one another, so that the hydration of $\mathrm{CD}$ and $\mathrm{MN}$ becomes interdependent, the hydration energy becomes less negative. Within the scatter, this energy becomes indistinguishable from zero in the most stable geometries for the complexes. 


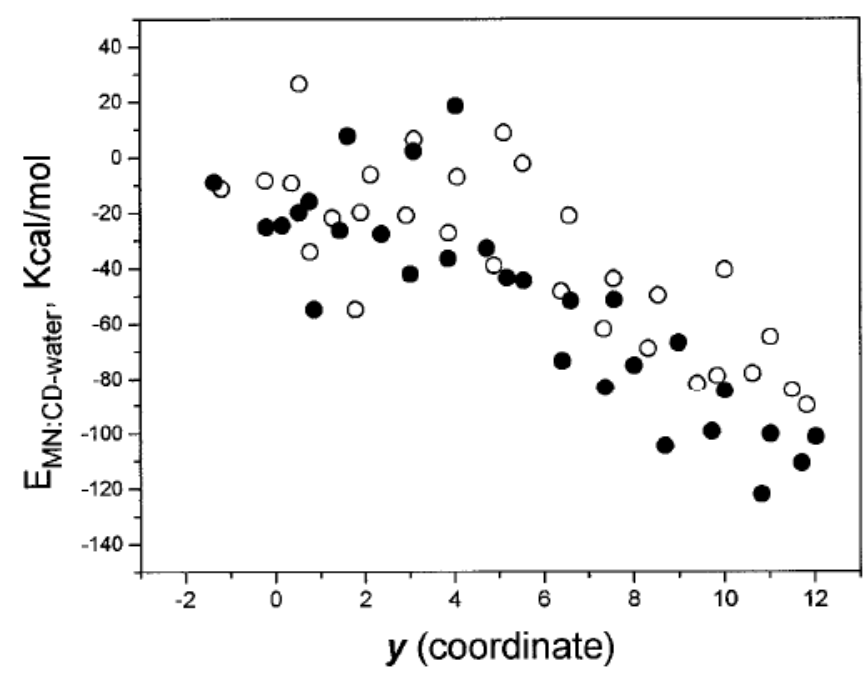

FIG. 8. Interaction energy between the water and the complex for (O) A and (•) B, obtained with Method II.

Therefore the hydration energy serves as a source of destabilization for the complexes.

\section{CONCLUSIONS}

MM calculations for the MN:CD systems in vacuo and in the presence of water as a solvent reproduce the experimental fact (49) that both 1:1 complexes are thermodynamically stable in water. The nonbonded van der Waals interactions are responsible for this stability, both in water and in vacuo. Complexation is accompanied by an increase in strain in the CD macroring. The energy of hydration favors the separation of $\mathrm{MN}$ from the $\mathrm{CD}$. The binding energy for the structure of minimum energy is more negative for the formation of $\mathbf{B}$ than for the formation of $\mathbf{A}$. This observation in the calculations agrees with the higher stability of $\mathbf{B}$ in the experiments. In the complex of minimum energy, $\mathrm{MN}$ penetrates completely through the cavity in the - -CD cavity, but it makes only a slight penetration into the cavity of - $\mathrm{CD}$. This difference in the structures of the two complexes may contribute to the differences in $-S$ for their formation.

\section{ACKNOWLEDGMENTS}

This research was supported by CICYT Grant PB94-0364, by the University of Alcalá, (UAH 017/95), and by National Science Foundation Grant DMR 9523278. We express our thanks to Mrs. Heijnen for assistance with the preparation of the manuscript.

\section{REFERENCES}

1. Bender, M. L., and Komiyama, M., "Cyclodextrins Chemistry." Springer-Verlag, Berlin, 1978.

2. Szetjli, J., "Cyclodextrins and Their Inclusion Complexes." Akadémiai Kiadó, Budapest, 1982.
3. Szejtli, J., "Cyclodextrins Technology." Kluwer Academic, Dordrecht, 1988.

4. Connors, K. A., "Binding Constants: A Measurement of Molecular Complex Stability." Wiley, New York, 1987.

5. Matsui, M., and Mochida, K., Bull. Chem. Soc. Jpn. 52, 2808 (1979).

6. Yorozu, T., Hoshino, M., Imamura, M., and Shizuka, H., J. Phys. Chem. 86, 4422 (1982).

7. Buvari, A., and Szejtli, J., J. Incl. Phenom. 1, 151 (1983).

8. Hamai, S., J. Phys. Chem. 93, 2074 (1988).

9. Smith, V. K., Ndou, T. T., Muñoz de la Peña, A., and Warner, I. M., J. Incl. Phenom. 10, 471 (1991).

10. Mularz, E., Cline-Love, L. J., and Petersheim, M., Anal. Chem. 60, 2751 (1988).

11. Harata, K., and Uedaira, H., Bull. Chem. Soc. Jpn. 48, 375 (1975).

12. Kobayashi, N., Saito, R., Hino, H., Hino, Y., Ueno, A., and Osa, T., J. Chem. Soc. Perkin Trans. 2, 1031 (1983).

13. Cromwell, W. C., Bystrom, K., and Eftink, M. R., J. Phys. Chem. 89, 326 (1985).

14. Diard, J. P., Saint-Aman, E., and Serve, D., J. Electroanal. Chem. Interfacial Electrochem. 189, 113 (1985).

15. Matsue, T., Osa, T., and Evans, D. H., Anal. Chem. 56, 722 (1981).

16. Matsue, T., Fujihara, M., and Osa, T., J. Incl. Phenom. 2, 548 (1984).

17. Mohseni, R. M., and Hurtubise, R. J., J. Chromatogr. 499, 395 (1990).

18. Fujimura, K., Ueda, T., Masashi, K., Takayanagi, H., and Ando, T., Anal. Chem. 58, 2668 (1986).

19. Dong, D. C., and Winnik, M. A., Photochem. Photobiol. 35, 17 (1982).

20. Blyshak, L. A., Dobson, K. Y., Patonay, G., Warner, I. M., and May, N. E., Anal. Chem. 61, 955 (1989).

21. Agbaria, R. A., Uzan, B., and D. Gill, D., J. Phys. Chem. 93, 3855 (1989).

22. Flamigni, L., J. Phys. Chem. 97, 9566 (1993).

23. Will, A. Y., Munoz de la Peña, A., Ndou, T. T., and Warner, I. M., Appl. Spectrosc. 47, 277 (1993).

24. Fraiji, E. K., Jr., Cregan, T. R., and Werner, T. C., Appl. Spectrosc. 48, 79 (1994).

25. Nakamura, A., Sato, S., Hamasaki, K., Ueno, A., and Toda, F., J. Phys. Chem. 99, 10952 (1995).

26. Hamilton, J. A., Steinrauf, L. K., and Van Etten, R. L., Acta Crystallgr. Sect. B 24, 1560 (1968).

27. Flohr, K., Patton, R. M., and Kaiser, E. T., J. Am. Chem. Soc. 97, 1209 (1975).

28. Kotake, Y., and Janzen, E. G., J. Am. Chem. Soc. 111, 5138 (1989).

29. Lipkowitz, K. B., J. Org. Chem. 56, 6357 (1991).

30. Linert, W., Margl, P., and Renz, F., Chem. Phys. 161, 327 (1992)

31. Dodziuk, H., and Nowinski, K., J. Mol. Struct. (Theochem.) 304, 61 (1994).

32. Prabhararan, M., and Harvey, S. C., Biopolymers 26, 1087 (1987)

33. Prabhakaran, M., Biochem. Biophys. Res. Commun. 178, 192 (1990).

34. Koehler, J. E. H., Saenger, W., and van Gunsteren, W. F., J. Mol. Biol. 203, 241 (1988).

35. Koehler, J. E. H., Saenger, W., and van Gunsteren, W. F., Eur. Biophys. J. 16, 153 (1988).

36. Pozuelo, J., Madrid, J. M., Mendicuti, F., and Mattice, W. L., Comput. Theor. Polym. Sci. 6, 125 (1996).

37. Harata, K., Bull. Chem. Soc. Jpn. 49, 197 (1976).

38. Tabushi, I., Kiyosuke, Y., Sugimoto, T., and Yamamura, K., J. Am. Chem. Soc. 100, 916 (1978).

39. Menger, F. M., and Sherrod, J., J. Am. Chem. Soc. 110, 8606 (1988).

40. Venananzi, C. A., Canzius, P. M., Zhang, Z., and Bunce, J. D., J. Comput. Chem. 10, 1038 (1989).

41. Ohashi, M., Kasatani, K., Shinohara, H., and Sato, H., J. Am. Chem. Soc. 112, 5824 (1990). 
42. Jaime, C., Redondo, J., Sánchez, F., Sanchez-Ferrando, F., and Virgili, A., J. Org. Chem. 55, 4772 (1990).

43. Caime, C., Redondo, J., Sánchez, F., Sanchez-Ferrando, F., and Virgili, A., J. Mol. Struct. 248, 317 (1991).

44. Fotiadu, F., Fathallah, M., and Jaime, C., J. Incl. Phenom. 16, 55 (1993).

45. Fathallah, M., Fotiadu, F., and Jaime, C., J. Org. Chem. 59, 1288 (1994).

46. Ivanov, P. M., and Jaime, C., Anal. Quim. Int. Ed. 92, 13 (1996).

47. Lipkowitz, K. B., Roghothama, S., and Yang, J., J. Am. Chem. Soc. 114, 1554 (1992).

48. Berg, U., Gustavsson, M., and Aström, N., J. Am. Chem. Soc. 117, 2114 (1995).

49. Madrid, J. M., and Mendicuti, F., Appl. Spectrosc., in press.
50. Clark, M., Cramer, R. C., III, and Van Opdenbosch, N., J. Comput. Chem. 10, 982 (1989).

51. Sybyl 6.2, Tripos Associates, St. Louis, Missouri, USA.

52. MOPAC.AM1, included in the Sybyl 6.2 package.

53. Brunel, Y., Faucher, H., Gagnaire, D., and Rasat, A., Tetrahedron 31, 1075 (1975).

54. Press, W. H., Flannery, B. P., Teukolski, S. A., and Vetterling, W. T., "Numerical Recipes: The Art of Scientifi Computing,"' p. 312. Cambridge Univ. Press, 1988.

55. Blanco, M., J. Comput. Chem. 12, 237 (1991).

56. Kano, K., Takenoshita, I., and Ogawa, T., Chem. Lett. Chem. Soc. Jpn. 231 (1982).

57. Nelson, G., Patonay, G., and Warner, I. M., Appl. Spectrosc. 41, 1235 (1987). 